\title{
Moral, género y gusto. Críticas cinematográficas alrededor del erotismo de Armando Bo e Isabel Sarli en Argentina (1968-1972)
}

\author{
Morality, gender and taste. Film reviews over Armando Bo and Isabel Sarli's \\ eroticism in Argentina (1968-1972)
}

Ailin Basilio Fabris

ailinbasiliofabris@gmail.com

Universidad Nacional de Quilmes, Centro de Estudios en Historia, Cultura y Memoria, Argentina

Recepción: 06 Febrero 2020

Aprobación: 20 Mayo 2020

Publicación: 01 Marzo 2021

Cita sugerida: Basilio Fabris, A. (2021). Moral, género y gusto. Críticas cinematográficas alrededor del erotismo de Armando Bo e Isabel Sarli en Argentina (1968-1972). Descentrada, 5(1), e137. https://doi.org/10.24215/25457284e137

\begin{abstract}
Resumen: El artículo estudia la recepción mediática de las producciones eróticas de Armando Bo e Isabel Sarli con el objeto de analizar cómo los críticos desarrollaron una preocupación en torno a su circulación e influencia social y cultural durante las décadas de 1960 y 1970. La discusión sobre el cine erótico entrañó presunciones de género y clase mediante las cuales los críticos propusieron nociones, sentidos y jerarquías sobre los efectos simbólicos y materiales de su consumo. Asimismo, el artículo se aproxima a las críticas de cine como fuentes históricas, al tiempo que considera a la prensa, los diarios y las revistas como arenas de disputa en la configuración de sujetos, sentidos y significados en perspectiva histórica.
\end{abstract}

Palabras clave: Prensa, Erotismo, Cinematografía, Género, Gusto, Discursos.

\begin{abstract}
This paper deals with the mediatic reception of Armando Bo and Isabel Sarli's erotic cinema in order to analyze how critics have developed a social interest over its cultural circulation and resignyfication during the sixties and seventies. The discussion over erotic cinema involved gender and class presumptions through which they propose notions, senses, and hierarchies on the symbolic and material effects of its consumption. Moreover, we approach these reviews as historical sources, while we consider the press, newspapers and magazines as battlefields disputing the configuration of subjects, senses, and meanings in historical perspective.
\end{abstract}

Keywords: Press, Eroticism, Cinematography, Gender, Taste, Discurses.

\section{INTRODUCCIÓN}

Este artículo estudia la presencia del cine erótico y las figuras de Armando Bo (1914-1981) e Isabel Sarli (1936-2019) en la prensa gráfica local durante las décadas del sesenta y setenta, a fin de conocer sus alcances fuera de las pantallas en términos de género e impacto cultural. ${ }^{1}$ En particular, se aboca al tratamiento que recibieron desde las páginas de la crítica cultural a razón del estreno de dos de sus films, Carne (1968) y Fuego 
(1969), y expone el lugar central que el cuerpo femenino, la moral sexual y los consumidores tenían en dicho análisis.

Desde el momento en que Bo y Sarli estrenaron su primera película en 1958, El trueno entre las hojas, las críticas del espectáculo revelaron miradas disímiles sobre el impacto que este cine tuvo en las audiencias y en la cinematografía de la época. Por un lado, repararon en los atributos técnicos y estéticos del mismo. Por el otro, sentenciaron la incapacidad de Sarli de ser algo más que la concatenación de desnudos, violencia exacerbada y espectadores enardecidos.

La literatura en torno a dichas producciones (Drajner Barredo, 2016; Foster, 2008; Goity, 2004a; Ruétalo, 2004; Capalbo y Valdez, 2004) soslayó los contornos y las derivas sociales y culturales, desestimando posibles relecturas y/o procesos de apropiación y de significación de identidades, subjetividades y representaciones sociales en torno al sexo y la sexualidad a escala local en la segunda mitad del siglo XX.

En simultáneo a la irrupción del cine, su abordaje se tornó atractivo para la incipiente industria editorial de las décadas del veinte y del treinta, creando espacios dedicados tanto a su intelección como a la vida privada y pública de sus protagonistas. Desde la historiografía, el estudio de la prensa posibilitó indagar el diversificado espectro de ofertas y actores en ella, priorizando la escala local urbana y el período histórico iniciado en entresiglos. Por un lado, fueron estudiados los vínculos con el Estado (Cane, 2012; Panella, 2000) y, por el otro, el rol desempeñado en determinados contextos históricos (Iturralde y Borrelli, 2019; Montrucchio, 2000). Sin embargo, la crítica de cine como espacio de producción de sentidos sociales y representaciones culturales ha sido escasamente abordada (Campos, 2016).

En consecuencia, el trabajo procura avanzar sobre esta línea y reponer la negociación de sentidos, significaciones y representaciones en el marco de relaciones sociales históricas. Para ello, argumenta que al reseñar el cine de Bo y Sarli, la prensa gráfica desplegó sentidos y discursos sobre el orden de género, al tiempo que ensayaba jerarquizaciones culturales fundadas en un gusto cultural. Este último se centró en las dimensiones morales de los consumidores y sus implicancias para la "cultura".

$\mathrm{Al}$ situarse en un cruce entre la historia social, los estudios de género e historia cultural, se problematiza la producción de los sentidos alrededor de la circulación y consumo cultural de este cine en actores subalternos (Tenti, 2012), como las operaciones de desigualación, definición y asignación de características femeninas o masculinas (Scott, 2008). Consecuentemente, coadyuva a complejizar el abigarrado escenario político, social y cultural de los entretelones posperonistas en materia de sexualidad y moral (D'Antonio \& Eidelman, 2019). Al referirnos al "gusto cultural”, buscamos matizar tanto las prácticas de jerarquización elaboradas por la prensa, como los intersticios dentro de los procesos de consumo de bienes culturales (Bourdieu, 1988; Wacquant, 2002).

Abordar las representaciones supone atender las dinámicas de articulación de sentidos que generan correspondencias y equiparaciones discursivas entre objetos y sujetos (Hall, 1997); pensar la variabilidad histórica de lo representado en un contexto de enunciación determinado (Chartier, 1991), y su gravitación en el ordenamiento de las diferencias sexuales en las relaciones sociales (Scott, 2008).

La elección de las fuentes audiovisuales estribó en la propia transición que el cine erótico atravesó a finales de los sesenta en relación a la representación del ejercicio de la sexualidad, el sentido del erotismo y la pregnancia de la figura de Isabel Sarli. Asimismo, el corpus heurístico se nutre de registros hemerográficos aparecidos en secciones de "espectáculo", "entretenimiento" o segmentos "culturales" de circulación urbana, que cubren las distintas instancias de estrenos. Dicho recorte responde al acceso y la conservación de documentación en los archivos revisados.

Para cumplimentar estos objetivos, el texto está organizado en cuatro apartados. El primero, presenta el panorama de la prensa gráfica, tomando como punto de partida el segundo lustro de los cincuenta, momento en el cual emerge este cine y se diversifica el mercado editorial. A continuación, exploramos el lugar que la crítica de cine, el espectáculo y las revistas especializadas fueron ganando para, finalmente, en los dos últimos apartados analizar la acogida y el tratamiento de las películas eróticas en diversos medios gráficos de 
la época, prestando especial atención a los vínculos, nociones y sentidos en torno al género, la sexualidad y las jerarquizaciones de clase vehiculizadas por dichos actores.

\section{LA CULTURA DESPUÉS DE 1955}

En la Argentina que devino después del golpe de Estado de septiembre de 1955, los entonces medios de comunicación vislumbraron que otra etapa se abría para su actividad. Si el vínculo entre la prensa gráfica y el gobierno peronista había sido polivalente (Rein y Panella, 2008), los sectores ligados al campo cultural e intelectual aventuraron que otras discusiones y reflexiones podían comenzar a germinar. De acuerdo a la historia intelectual y política, los principales debates y discusiones gestados al interior de los círculos intelectuales y universitarios orbitaron no sólo respecto al peronismo como fenómeno, sino a reflexionar qué escenarios comenzaban a abrirse en América Latina y qué significantes signarían las políticas sociales estatales locales en el marco de la segunda posguerra, la Guerra Fría y la avanzada autoritaria (Terán, 1991, 2008; Osuna, 2017).

Los materiales culturales que circulaban en los años sesenta han sido considerados andamiajes cardiales en el transcurso de estas dinámicas, localizándose como focos de abordaje y enunciación de nuevas problemáticas, difundiendo posiciones y percepciones en torno a una agenda actualizada que diera cuenta de los temarios diarios (Becerra, 2010). Según investigaciones recientes, tanto diarios como revistas emprendieron una renovación y ampliación del repertorio de noticias vinculadas a esta "modernización", como la sexualidad, la juventud y la familia, para gozar de un público más amplio (Cosse, 2012; Manzano, 2017). Los heterogéneos repertorios que la prensa gráfica indicaba y tallaba, formaron parte de un engranaje que empujaba hacia esa "modernización" y una renovación que buscaba ser fomentada por divergentes actores sociales (Pujol, 2007).

Casi dos años después del golpe de Estado de 1966, un proceso de recambio comenzaba a delinearse en los pasillos y las oficinas de redacción de las diversas editoriales de la época. Una camada de jóvenes escritores y periodistas ingresaban al heterogéneo territorio de los medios de comunicación para proponer otros estilos de difundir y entender el quehacer de la prensa gráfica local (Ulanovsky, 1997). La variedad de espacios dejaba entrever el sincretismo que el plano cultural atravesaba en materia de comunicación, pero, también, el impulso por revisar el pasado reciente, causando una fascinación, tanto para el periodismo como para los círculos intelectuales de la época.

Un hito importante en cuanto al dinamismo del campo cultural lo tuvo la aparición de la televisión privada a finales de la década de los cincuenta. A pesar de que la primera transmisión data del año 1951, el boom televisivo emergió en el año 1958, creciendo a través de la diversificación de distintas señales, principalmente privadas, y transfigurando los modos de entender la vida cotidiana y las dinámicas sociales y culturales de la época (Varela, 2005).

Los sesenta, vistos desde la comunicación, han sido caracterizados como años de fuerte competencia en la prensa gráfica en relación al control de la información, la cantidad de tiradas diarias y la adquisición de publicidad como fuente de financiamiento (Getino, 2008).

De acuerdo a Mónica Bartolucci (2006), el problema de la modernización de la esfera cultural se tornó una preocupación para el entonces Poder Ejecutivo de facto encabezado por Juan Carlos Onganía (1966-1969), quien no veía con buenos ojos el consumo de diarios y revistas "modernas" por parte de los jóvenes y las familias, pues podían "descomponer" los hábitos de vida tradicional. Por ello, se reunió con los editores de ocho revistas de información general editadas en Buenos Aires, Panorama, Siete Dias, Primera Plana, Extra, Gente, Confirmado, Atlántida y Análisis, para transmitirles un mensaje de morigeración frente al tratamiento de su gobierno, pero también de un respeto a cierto consenso social ligado a valores tradicionales: la familia, la unidad y la paz social. 
A través de revistas como Primera Plana o Confirmado fueron vehiculizadas distintas aristas en el seno de los planos social, político y cultural de principios de los sesenta. Mientras que Primera Plana fue fundada por Jacobo Timermann en 1962, y tenía como crítico literario y cinematográfico al escritor y periodista Tomás Eloy Martínez, ${ }^{2}$ Confirmado nació de la ruptura del primero con Primera Plana hacia 1965. En este sentido, sendas plataformas discurrieron sobre sexualidad, música, moda, cine y literatura, ayudando a cimentar una lógica del quehacer periodístico concebido como moderno hacia fines de los cincuenta y durante la década del sesenta (Ulanovsky 1997), interpelando a emergentes sectores juveniles (Cammarota, 2014).

De acuerdo a Ford y Rivera (1985) entre 1960 y 1970, cinco diarios dominaron la tirada diaria dentro del radio capitalino: Clarín, La Nación, Crónica, La Razón y La Prensa. En simultáneo, se desarrollaba un mercado editorial orientado a revistas semanales, de interés general y con una perspectiva de consumo dirigida a sectores medios.

La contemplación dada por los medios de comunicación a la vida cultural local en la segunda mitad del siglo XX permeó los medios gráficos dedicados al cine, al teatro y a la literatura. Las revistas especializadas se volcaron a una mayor profesionalización de la actividad periodística, que incluyó emular los estilos de tabloides estadounidenses, interesándose en aspectos metodológicos y estéticos del lenguaje cinematográfico (Goity, 2004b).

En ese diversificado mercado de revistas, una editorial de raigambre familiar como Abril (1941-1976) proponía ahondar en el terreno de publicaciones eróticas o de adultos al estilo norteamericano de Playboy, cuyas páginas contenían una sinergia de intereses que excedían la mera exhibición de desnudos femeninos. A la par de una circulación y consumo del cine erótico local, una revista como Adán (1966-1968) articuló las tensiones que suscitaban las mutaciones en las pautas de consumo, de sociabilidad y de género con un periodismo gráfico al servicio de un modelo masculino profesional urbano (Giordano, 2014). En ese marco, la puesta en escena del erotismo, tanto gráfico como audiovisual, no resultaba ajena, sino que revelaba las fricciones que existían en la regulación de los cuerpos y las pautas “modernas” que concitaba la prensa gráfica en los sesenta (Eidelman, 2015; Schaufler, 2017).

Esta abigarrada postal propone una aproximación a los diversos intereses que emergían y se nucleaban en torno a las editoriales y periódicos de la época. A su vez, el paso del tiempo dio lugar a una renovación, tanto de temáticas como de sus actores, abonando por una idea de periodismo y de un lenguaje moderno que amalgamase tanto los planos internacionales como los locales. Circunscriptos a un epicentro urbano, tal disposición espacial nos infiere a preguntarnos por las plumas de tales producciones y los sectores a interpelar.

\section{EsPesando El gusto: ReVistas de espectáculos y los CRíticos de CiNe}

Promediando la década del treinta, con el nacimiento de la radio y el arribo del sonido al cine, la prensa gráfica absorbió las emergentes innovaciones como posibles objetos de interés en aras de construir e interpelar nuevos públicos. En consecuencia, las denominadas "revistas de espectáculos" tuvieron como objetivo presentar y describir tanto el carácter íntimo de los protagonistas de la radio o el cine, como también aquello que sucedía en sus vidas personales, elaborando un escenario liminal entre ellos y los consumidores. La convergencia de la radio, el cine y el teatro se entrelazó con una pujante producción editorial (Calzón Flores, 2012; Eujanian, 1999).

$\mathrm{Al}$ avanzar el siglo XX, la cuestión de la coyuntura social, política y económica irrigaba los espacios dedicados a la crítica literaria y de espectáculos. Hacia mediados de la década de los cincuenta, la conformación de cineclubs y sus órganos de difusión en formato de revista, como Tiempo de Cine o Gente de cine, abonaron a la configuración y la circulación de un saber, anclado en disposiciones y presupuestos acerca de lo "cultural" y la "cultura", que habilitaba la intervención en el debate por la "modernidad", el rol del arte y la transformación cultural que adveniría con el derrocamiento del peronismo (Broitman, 2014, 2016). 
Es en este complejo escenario, que la crítica de cine buscó plasmar no sólo el análisis sobre películas y la cinematografía, sino también propiciar reflexiones sobre el orden social y politico del país. Según Goity (2004c), la promulgación de la Ley de Cine en 1957, que lo homologó como medio de expresión equivalente a la radio y a la prensa escrita, promovió la aparición de críticos en los medios de comunicación y con ello dio lugar a otro tiempo para el cine.

Como hemos desarrollado, una amplia gama de revistas especializadas en cine y espectáculo coexistían y se distinguían de acuerdo a sus diseños y el precio, pero también por el tipo de interlocutor y el posicionamiento dentro del campo cultural. En cuanto al cine, Cinegraf, El Heraldo del Cinematografista, Cine crítica, Mundo de Cine, Gente de Cine y Tiempo de cine, fueron algunas de las revistas que vieron la luz desde la década del veinte hasta los sesenta. Por otro lado, diarios y revistas como Clarín, La Nación, Primera Plana, Panorama, La Prensa, Crónica, Ámbito Financiero, La Opinión, Critica, Mundo Argentino, El Mundo y La Razón, poseían secciones y columnas dedicadas a la recepción y al tratamiento de diversas películas, tanto nacionales como extranjeras.

Una marca distintiva de las críticas de cine era que se firmaban con las iniciales del autor o bajo seudónimos, porque sólo pocos diarios accedían a que los críticos firmaran con su nombre e identidad completa (Goity, 2004a). El desarrollo de un discurso cinematográfico propio bajo la forma de la crónica de cine, venía cobrando fuerza desde su autonomización como campo (Callegaro, 2014) y a través del impulso de las emergentes consideraciones y concepciones que el cine local elaboraba sobre su propia práctica (Oubiña, 2016). Todos estos indicadores dan cuenta de que el cine y sus entretelones anidaron como fenómenos de largo aliento a través de revistas como Cinegraf $\beta$ o El heraldo del cinematografista en tanto comenzaba a cobrar alcances y consumos amplificados. ${ }^{4}$

En el caso de Armando Bo e Isabel Sarli, sus trayectorias constituyeron un foco de atención de largo aliento en la prensa de espectáculos local. En sus inicios, Armando Bo se dedicó a la actuación cinematográfica, principalmente protagonizando películas que lo consagraron como astro popular. Por otro lado, Sarli había ejercido como secretaria en la Marina Mercante y luego como modelo gráfica, alcanzando popularidad gracias a su coronamiento como Miss Argentina en 1955.

En cuanto al caso de las revistas de espectáculos, como Radiolandia, TV Guía y Sintonía, el ideal de proximidad que pretendían delinear entre figuras reconocidas y lectores desdibujaba los límites entre el espacio público y el privado, en especial si este proceso de consumo es considerado desde una óptica de género y clase. Aventuramos que el estilo estético que las revistas de espectáculo construían y la prosa accesible, junto con estereotipos de "galanes" y "divas", descansaban en una feminización, una domesticidad del consumo y de interpelación de clases populares y capas medias bajo el supuesto de un componente "natural” en las mujeres que las hacía propensas a interesarse en lecturas y consumos "banales", como la vida personal de renombrados artistas. En la Figura 1, TV Guía acentuaba el carácter internacional de Sarli como una figura popular y de alcance masivo, mientras que Platea (Figura 2) morigera la exaltación corporal de la actriz.

De esta manera, las críticas de cine que aparecían en las revistas de espectáculos aducían un registro escrito claro que no pretendía ensimismarse en tecnicisimos ni en miramientos estéticos alrededor del cine, sino en brindar espacios para el ocio y el entretenimiento. No obstante, las crónicas ponían en tensión sus propias nociones e imaginarios sobre los lectores, los consumidores y los potenciales espectadores de dichos filmes. 


\section{FIGURA 1}

Isabel Sarli en la Revista $T V$ Guia, N $^{\circ} 1538,1$ de noviembre de 1960

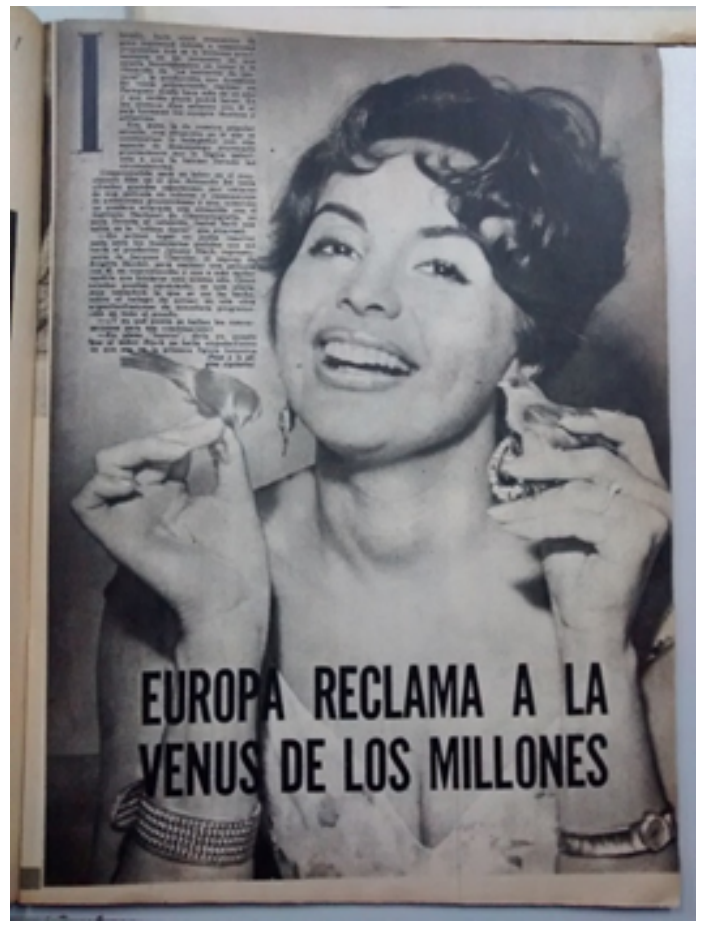

No obstante, por fuera de la órbita del espectáculo, la prensa era más bien refractaria a enaltecer los numerosos estrenos de sus películas, o atender la vida privada de reconocidas figuras del cine, radio o teatro. En efecto, esta divergencia nos induce a conjeturar el peso de las disposiciones de género y los posicionamientos de clase en la diversificación del mercado editorial, como también en los accesos y consumos culturales, lo que suponía un conjunto de expectativas y las representaciones acerca de los lectores/ consumidores.

En una nota publicada en el diario El mercurio, Bo realizó un descargo contra el sindicato de críticos de cine que, a lo largo de los años, habían desprestigiado, menospreciado y cuestionado la clase de cine que hacía, tomando como blanco principal a Isabel Sarli y a otras actrices del medio (Convicción, 3 de abril de 1980). En este punto, el cineasta entendía que la distancia entre su noción de cine y la comprensión de este por agentes culturales era de clase, en virtud de una animadversión al origen social de la actriz y de las tradiciones y costumbres que nutrían a sus narrativas. 
FIGURA 2

Isabel Sarli en la portada de Platea, año 3 N82, 16 de octubre de 1961.

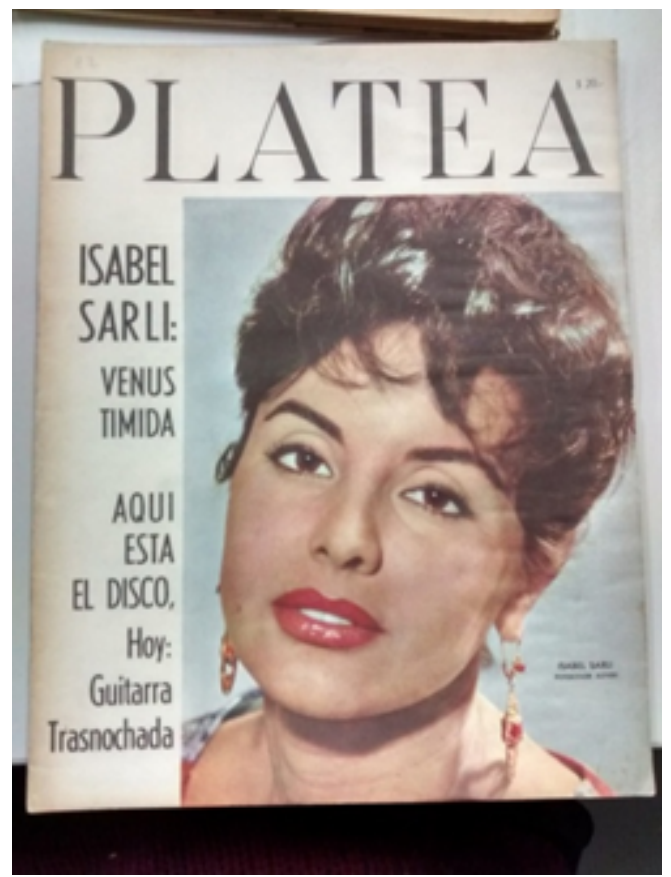

Si las palabras del cineasta nos arrojan luz sobre algunas de las matrices que anidaban y operaban en la construcción del gusto en las crónicas de cine, podemos aventurar que dicho proceso no se encontró al margen de las cuestiones de clase y género, e irradió tanto a la actriz y al cine del que participaba, como también a quienes lo consumían.

\section{LA REPRESENTACIÓN DE LA MORAL: CARNE COMO METÁFORA DE LA CULTURA PATRIARCAL}

En octubre de 1968, un cúmulo de diarios y revistas locales dejaron entrever el inminente estreno de una nueva película dirigida por Armando Bo y protagonizada por Isabel Sarli denominada Carne, cuyo argumento estribó en narrar los diferentes escenarios y situaciones de violencia sexual protagonizados por una trabajadora de un frigorífico. De acuerdo a las fuentes relevadas, Carne transitó, al menos, por tres instancias de estreno y cobertura mediática: su lanzamiento original y programado para 1968, y sus reestrenos en $1979 \mathrm{y}$ en 1982. Cada una de estas tres escenas se encuentra impregnada por los marcos sociales, culturales y políticos por los que transitaron.

En el primer caso, se asistía a campañas de moralización que tenían por objeto "sanear" a la población argentina y a la cultura nacional de la obscenidad, del comunismo, de la amoralidad, y así reinstalar las "buenas costumbres" y los valores católicos (Cousins, 2008). En el interregno entre los dos estrenos, en el que se sucedieron la deposición de Juan Carlos Onganía (1966-1970), nuevos golpes de Estado, elecciones democráticas, el retorno de Juan Domingo Perón a la Argentina, su fallecimiento y la puesta en marcha de un plan nacional sistemático de desaparición forzada de personas, había cribado otra cartografía social. Finalmente, el tercero tuvo lugar en un período de transición política para la sociedad y la institucionalidad vernácula, en tanto en el horizonte se vislumbraba la recuperación de la democracia tras una luctuosa y feroz dictadura que permeó todos los niveles y planos de actividad social, cultural, política y económica.

En la reseña aparecida en el diario La Nación, la lectura que se hace del personaje femenino condensa los sentidos propuestos por el filme en sí mismo, como la necesidad de ratificar el único propósito para la participación de la actriz en el cine argentino: 
(...) encarna a una muchacha de provocativa y desbordante belleza que trabaja en ese establecimiento y que, sin quererlo, despierta toda una suerte de bajas pasiones entre los hombres que se mueven en ese mundo rudo y agresivo de la industria de la carne (...) (La Nación, 26 de octubre de 1968).

En este sentido, el énfasis en el atributo físico de la actriz es asumido por el crítico como una cualidad natural que las mujeres deliberadamente explotan: provocar y atenerse a las consecuencias de la exhibición y participación, tanto fuera como dentro de la pantalla grande.

La cuestión de cómo enunciar la violación alumbra las operaciones de poder a la hora de nombrar los fenómenos sociales y culturales. En efecto, al emplear eufemismos como "bajas pasiones", "ultrajes", "brutal atentado colectivo", "realidad patética" o "vejámenes", se atiende a un desplazamiento del foco problemático: en tanto el uso de la violencia se asumía como una respuesta física "natural" que los hombres manifestaban ante la "provocación" femenina, simbólicamente la violación no era significada como vulneración, sino como apropiación y mineralización de una masculinidad precaria (Segato, 2003).

A su vez, la doble pauta moral operó a la hora de naturalizar tales designios: el título del artículo resumió al filme como una mera lucha entre hombres por un "pedazo de carne”, es decir, el cuerpo femenino se homologó como objeto de consumo masculino, el cual se solapaba con ideales y prácticas de masculinidad ancladas en un bastión de una cultura popular local como la carne.

La relación enhebrada entre la carne y la masculinidad se concibió como simbiótica dado que, en términos culturales, cocinar y preparar un asado, acciones que aparecen en Carne, implicaron una ritualidad encarnada por varones; a escala local, a la carne le fue asignada una significación masculina y, a través de su consumo, se forjó la construcción de la hombría y la virilidad. ${ }^{5}$ En el reverso, la connotación del consumo de carne asumía la apropiación del cuerpo femenino: Isabel Sarli era intrínsicamente una mercancía apropiable por varones.

En sintonía, Crónica resaltó como elemento nodal las preocupaciones por "el sexo y el deseo", fundamentales en la filmografía de Armando Bo (Crónica, 26 de octubre de 1968). En sintonía con La Nación, asimiló al ambiente del rubro frigorífico como enclave de trabajo que construía "hombres de bajos instintos" y mujeres de dudosa reputación, es decir, una clase trabajadora considerada como indecente y sórdida. Estas reflexiones, lejos de ser antagónicas con su contexto, se inscriben en un imaginario social y cultural de largo aliento en torno a la peligrosidad de los frigoríficos y quienes trabajaban en ellos (Lobato, 2004).

En la resignificación que Carne plasmó en torno a las clases trabajadoras, las crónicas decodificaron al filme desde una clave higienista, es decir, adhirieron y reforzaron la configuración cultural e histórica del frigorífico como enclave procaz, violento y grotesco, germinador de masculinidades violentas y lujuriosas producto de condiciones de trabajo que exigían cuerpos vigorosos y una contención libidinal (Lobato, 2019). La participación femenina en el rubro de la carne se enquistó en ese entramado discursivo que posicionó a las mujeres como figuras receptoras, pasivas, pero también masculinizadas. Dichos escenarios, no obstante, no fueron privativos de la industria frigorífica, sino que alcanzaron a otras actividades, como la industria pesquera marplatense (Cutuli, 2011).

A su vez, el consumo de estas representaciones se tornó una preocupación para la prensa. El artículo advertía que dicha dinámica se sostenía en base a espectadores masculinos ya que el rostro y la "exuberancia" corporal de Isabel Sarli concitaban masculinidades receptoras a dichas alocuciones; masculinidades que podían ser peligrosas para la sociedad. En general, las narrativas en torno al cine erótico prescribieron de manera lineal y homogénea al consumo desde el estatuto heteronormativo, erigiendo a los varones en un rol de sujetos deseantes en contraposición con el de las mujeres, concebidas como pasivas y carentes de deseo.

El diario La Razón consideró a Carne como un "drama histórico con dosis de pintura costumbrista y toques de humor. La localización en un ambiente humilde, marginado y de “aparente civilización” se ofuscó como resultado de las reiteradas violaciones. La historia que compone el film no es más que "las desventuras de una humilde obrera de un frigorífico [...] que se ve atravesada por una serie de violaciones a manos de un hombrón sin escrúpulos impulsado por sus bajos instintos" (La Razón, 25 de octubre de 1968). Al naturalizar 
el contexto social y material precario de los sectores populares, la prensa reforzó un orden patriarcal que consignaba positivamente la representación de masculinidades violentas y virilizadas y la regulación del cuerpo y la sexualidad de las mujeres en favor de los primeros.

En un contrapunto con los anteriores documentos, La Razón tomó postura frente a los hechos: ratificó la violencia sexual al entramarla dentro de una semántica patriarcal en la cual las características físicas y exteriores femeninas confabulaban para crear formas de consumo masculinizantes, en las que las mujeres operaban en tanto objeto y hacedoras de su propia violencia: En los suburbios de Buenos Aires, en la zona de los frigoríficos, con sus callejuelas de casas humildes, sus zanjones de agua
servida, es decir, en un lugar marginado de la ciudad supuestamente civilizada, se ubica la acción de "Carne", una historia
dramática (...) Armando Bo se ha propuesto narrar con el empeño que lo caracteriza, destinada a inquietar o a emocionar a
un público sin exigencias que puede, incluso, proyectarse en algunos de sus personajes, o hallar un simple pasatiempo a sus
anhelos eróticos reflejados en la presencia de Isabel Sarli y sus turgentes formas. El drama no es más que las desventuras de
una humilde obrera de un frigorífico que es humillada y violada por un hombrón sin escrúpulos impulsado por sus bajos
instintos(La Razón, 25 de octubre de 1968).

Por su parte, La Prensa determinó que el cine de Bo y Sarli profundizaba la circulación de estereotipos de género en los que aparecían siempre mujeres de "buenas costumbres" y hombres "libidinosos" (La Prensa, 26 de octubre de 1968). Elaborada por el crítico católico Jaime Potenze, en ella podemos rastrear un lenguaje enquistado en su trayectoria como militante de la Acción Católica Argentina (ACA). ${ }^{6}$ Según Potenze, el frigorífico proponía una representación especular sobre las subjetividades estereotipadas que lo componían, como el de la mujer receptáculo, víctima, y el varón obrero incontenible, producto del ajetreo laboral. En este sentido, rotula a Isabel Sarli como "la Marilyn Monroe de Argentina", cuya connotación, lejos de ser positiva, abona a su construcción como un objeto de deseo a la vez ingenuo y pasivo. Frente a esa imaginería cultural, aventuramos que estos cronistas entrevieron en Sarli un modelo arquetípico de feminidad que reposaba en aspectos exclusivamente físicos, lo que suponía tanto una subestimación androcéntrica sobre las capacidades de las mujeres como sentidos preconcebidos sobre quienes asistían a verla.

De manera semejante, un denominador común en el que repararon las críticas de cine fue el denuesto social y cultural hacia los seguidores del cine erótico. Cuando Potenze apeló al público, evocó una idea de espectadores sumisos y legos, cuyas aspiraciones culturales sólo podían circunscribirse a productos mercantiles repetitivos y esquemáticos como el de Bo y Sarli. La jerarquización cultural y la condena moral que Potenze cribó en relación a la circulación y consumo del cine erótico, y que resonaba en otras voces periodísticas, reposó en el supuesto de que, lejos de ser inocuas y marginales, esas prácticas y representaciones buscaban interpelar a audiencias con características similares a las que presentan en sus filmes, es decir, agentes cuya moralidad estaba próxima a lo lascivo, lo impúdico y lo obsceno.

Al disponer de una grilla clasificatoria, la Gaceta de los espectáculos encasilló a Carne con "Muy buena" en la sección de recaudación en boleterías, pero "Buena" en calidad, acompañándola con "Entretenida" y "Prohibida para menores de 18". En ese sentido, la destacó como una película de humor en la que la broma principal consistió en la violencia sexual.

La coincidente regularidad con la que la prensa observó el trasfondo realista, ingenuo y costumbrista del film, se montaba sobre una mirada patriarcal que suponía la construcción del cuerpo femenino como objeto disponible para el varón. La representación de la sexualidad femenina que se utiliza en la Figura 3 adscribió a estas prerrogativas de género, reforzándolas. 
FIGURA 3

Poster de Carne

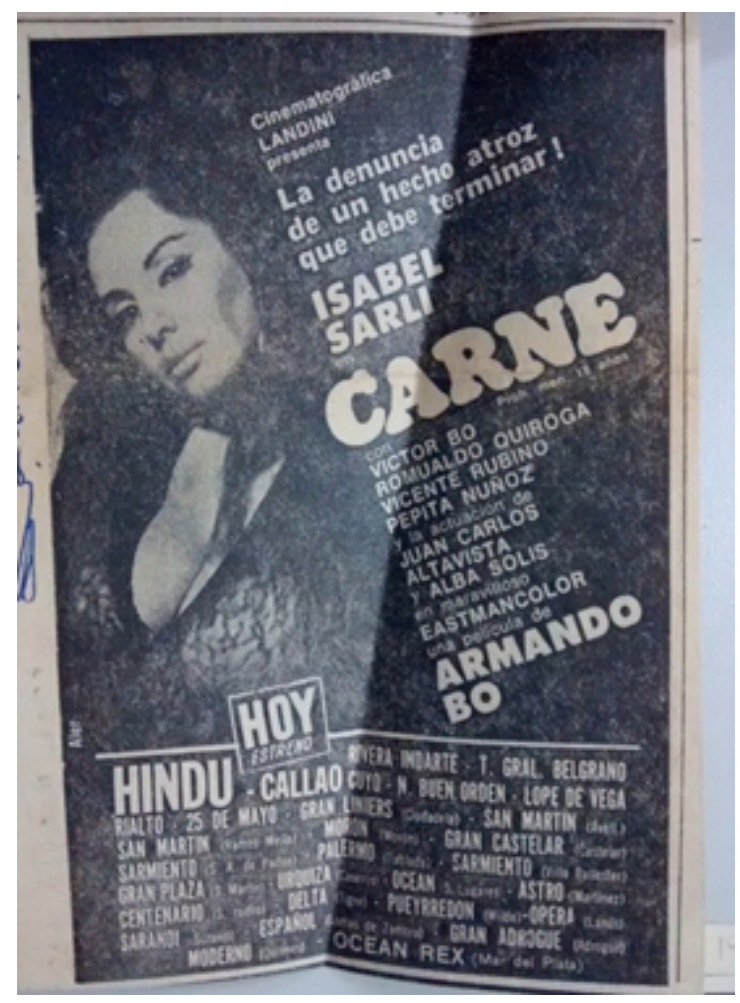

Fuente: La Prensa, 24 de octubre de 1968

La revista Radiolandia enfatizó el "realismo" de la película al argumentar que estuvo basada en "hechos reales" y que la historia de la película se trazó en base a una muchacha que se veía asiduamente asediada por un grupo de "seres desalmados" que sólo buscaban satisfacer "bestiales instintos". Con la misma tónica, la revista exaltó y reprodujo la imagen del frigorífico como espacio de masculinidades violentas, de prácticas de "malvados, desalmados, poco honrosos, viles" cuyo botín era Isabel Sarli (Radiolandia: el estreno de la semana, 10 de noviembre de 1968). El poster (Figura 3) refuerza la "atrocidad" de un modo ambivalente al plantear al filme como medio de denuncia social sin abandonar la sugerente figura de Sarli. De manera reiterada, el soslayamiento discursivo de la violación naturalizaba la construcción de los trabajadores como sujetos violentos, nerviosos e incontenibles, como consecuencia del trabajo en la industria de la carne, al tiempo que los atizaba moralmente.

En las revistas Panorama(29 de octubre de 1968) y Confirmado (31 de octubre de 1968), las reseñas en torno a Carne sintetizaron el argumento de la película, la participación de Isabel Sarli y el tópico de la violación. En la primera, se conceptualizó a la cinta como una pieza de humor involuntaria que tomó lugar en los frigoríficos. Esta sucinta mirada anuló las diferentes lógicas de género trazadas en la representación del espacio del frigorífico y, al categorizarlo como documental, lo dotó de una verosimilitud que reforzaba linealmente el retrato de la violencia. En consonancia, Confirmado lo vinculó al género documental, proponiendo una lectura de factura "realista" en torno a los frigoríficos. Así, el gusto cultural no horadaba el imaginario común del trabajo en el frigorífico, y la organización y la gestión de las relaciones sociales en torno a él, como enclaves violentos y precarios, sino que avanzaba en el refuerzo de representaciones y sentidos peyorativos sobre la vida cotidiana de los sectores populares sobre la base de un escaso capital cultural.

El heterogéneo grupo de crónicas nos permiten, en un primer momento, reconocer la importancia que el cine erótico de Bo y Sarli condensaba sobre el final de los sesenta y principios de los setenta. Desde la perspectiva de la prensa, tal trascendencia fue leída, por un lado, como una preocupación por los posibles 
efectos que podía suscitar su consumo y, por el otro, como un espacio para trazar jerarquizaciones culturales, entre buena y mala cultura, y dispensar narrativas androcéntricas sobre los límites de la agencia de las mujeres.

\section{LO FEMENino COMO PATOLÓgico: LecCiones DE GÉNero EN LA PRENSA EN LA RECEPCIÓN DE FUEGo}

Casi un año después del estreno de Carne, llegó a las pantallas Fuego. En esta ocasión, la película versó sobre la relación homoerótica entre dos mujeres, la pulsión heteronormativa masculina y el cuerpo femenino como vector de patologización biomédica. ${ }^{8}$ Una vez que los organismos censores y de calificación prescribieron su prohibición en 1969 (Confirmado, 1 de agosto de 1969), la oportunidad de promocionar el largometraje en el exterior se volvió plausible a instancias del disfrute de sus consumidores vernáculos y la condena cultural de sus detractores (La Nación, 17 de octubre de 1970; La Prensa, 28 de octubre de 1969; La Razón, 15 de octubre de 1970).

De acuerdo a las fuentes relevadas, existieron dos momentos respecto al estreno de Fuego: su censura y notoriedad internacional en 1969 y 1970, por un lado, y su postergado y dispar estreno en Argentina en 1971, por otro (Crónica, 11 de septiembre de 1971). El poster promocional aparecido en los tabloides estadounidenses devela parte del circuito transnacional de su consumo, al mismo tiempo que conjetura su utilización para exponer la tensa relación que existía entre los censores locales y Bo y Sarli a la hora de negociar los estrenos. Finalmente, el debut cinematográfico de Fuego en Argentina se aplazaría hasta dos años después.

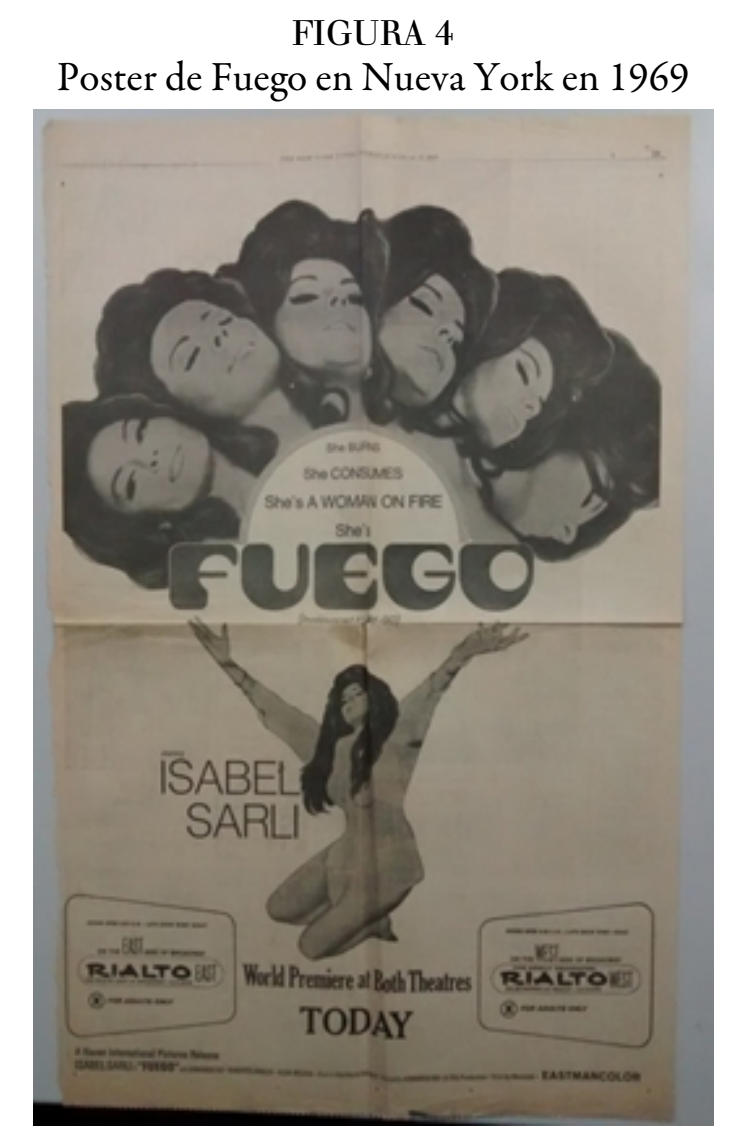

Fuente: The New York Times, 10 de octubre de 1969, p. 35.

En septiembre de 1971, diferentes plataformas gráficas dieron cuenta del dilatado estreno de Fuego en la Argentina. En una editorial de septiembre, Radiolandia describía con lujo de detalles el argumento central de la película a los ya conocidos seguidores de la pareja (Radiolandia, 24 de septiembre de 1971). En un rincón 
superior, la nota inscribía al filme como una producción a color, "un filme argentino", criollo, presentado por la industria Columbia Pictures, pero que igualmente era nacional. Con ello, la crítica no sólo se refería a las tensiones entre el director y las autoridades cinematográficas, sino también a sostener a Sarli como un ícono local.

Por su parte, Clarín recuperaba la similitud entre la representación y la realidad de la ninfomanía: “(...) y sus trágicas consecuencias para quienes la padecen y para los que aman a las enfermas (...)” (Clarín, 25 de septiembre de 1971). Inmediatamente, la crónica daba cuenta de que el potencial realismo quedaba eclipsado por la racionalidad erótica reiterada en las producciones de la dupla y con notable asidero entre sus consumidores. En una lectura a contrapelo, la crítica cultural de Clarín sugería una correspondencia entre la enfermedad retratada en la película y el cine erótico como una dolencia, una afección heteronormativa en tanto patologizaba a los espectadores por amar con el mismo fervor a la protagonista, la "enferma" del filme, como Sarli a los hombres y al sexo. En contraposición, la nota entronizaba a Bo como uno de los "pocos autores cinematográficos del cine argentino" por su coherencia y su enraizamiento con la "cultura tradicional", es decir, por apelar a lo "popular".

A su vez, La Razón abría su crítica mencionando la exuberancia física de Isabel Sarli como principal factor para su éxito y popularidad (La Razón, 24 de septiembre de 1971). Asumiendo, como su congénere periodístico, una correspondencia entre el público y la actriz, la nota encarama al filme y a los actores, en especial a Sarli, porque la considera una mujer devota a sus seguidores. La "entrega" se encarna en una prerrogativa maternal, abnegada y abocada a sus fanáticos; concomitantemente, un pasaje refuerza el cuerpo de Sarli como un objeto sexual: el papel de Laura, una ninfómana, tiene una cierta correspondencia indirecta con las disposiciones y comportamientos que la actriz porta en tanto una figura sexual convertida en fantasía para las audiencias.

El diario La Prensa enfatizó una banalización de lo "real” cristalizada en Fuego: “(...) los resultados de Fuego superan lo imaginable. Se hace difícil intentar siquiera un análisis serio de una producción obviamente dirigida a finalidades de tipo comercial, lamentablemente emparentada con una subestimación del público muy poco edificante (...)" (La Prensa, 24 de septiembre de 1971). El problema del público aparece con mayor fuerza aquí ya que delineaba un prototipo de consumidor como próximo a lo inculto; una otredad semantizada como analfabeta y lega. El que se inscribiese dentro del género folletín, radio teatro o fotonovela, revelaba que un sector de la crítica establecia jerarquías sociales y culturales respecto del consumo de ciertos bienes de índole popular y masiva.

La revista Primera Plana fue aún más elocuente sobre Fuego (Primera Plana, 28 de septiembre de 1971). La manera de describirlo marcaba una diferencia con el resto de los documentos pernotados: nominaciones como lesbiana e invertida para referirse al papel interpretado por Alba Mujica, la ama de llaves, revelan una atención hacia el deseo homoerótico, a pesar de que en el filme no son nominalizadas ni autopercibidas bajo una identificación lesbiana, pero bajo un enraizamiento peyorativo que lo erige como patología a partir de una cosmovisión heteronormativa. ${ }^{9}$ Asimismo, la crítica reconoce el impacto social que Fuego podría fomentar en los consumidores debido a que, desde su visión, incorporaba "temáticas modernas": "ha expuesto con valentía un problema que afecta a más de una mujer, un caso clínico". Esta lectura heteronormativa subsumió al lesbianismo como parte de un cuadro de dolencias en el que la ninfomanía podía revelar otras patologías, tales como el amor entre personas del mismo sexo.

Días más tarde, la revista publicaba una réplica hecha por una lectora en la que la demandante cuestionaba la política editorial en torno a la ausencia de críticas de producciones nacionales, como también el caso omiso a ciertos detalles que hacían al desempeño de Isabel Sarli, la consumación del coito y hasta el simbolismo en la vestimenta del personaje de Isabel Sarli:

(...) Otra: ella (Isabel Sarli) no está vestida de gala al suicidarse, sólo tiene puesto un deshabillé blanco y transparente, como corresponde. La última: hay, sí, un acto sexual que se realiza en la cama: es la protagonista con el señor Oscar Valicelli. ¿No vio el crítico esa parte? (Primera Plana, 5 de octubre de 1971). 
Inmediatamente el crítico arguyó que la vestimenta insinuante que la protagonista utilizaba al morir era homologable a la vestimenta que la actriz utilizaba en la vida real, deslizando el supuesto que Sarli adolecía de decoro y su honor no podía ser restituido. La moralidad sexual del discurso periodístico conminaba el ejercicio de una feminidad por fuera de las pautas de género prescriptas para las mujeres, tensionando la flexibilización de la agencia femenina en los sesenta (Cosse, 2010). De acuerdo al crítico Jorge $\mathrm{H}$. Andrés del diario La Opinión, el cine erótico era una producción lejana a lo artístico:

(...) de esta manera, la burla es siempre la conclusión final y de lo único que no resultan culpables estas obritas económicas es de sacrificar la libertad con que siempre trabaja este fértil realizador (...) algo de exhibicionismo y una obligación asumida de entregar regularmente su retoque a una mitología en la que se cree ciegamente, la de Isabel Sarli (...) (La Opinión, 25 de septiembre de 1971, p. 21).

A partir de argumentos basados en la lógica de rentabilidad, la figura de Sarli se asimiló a una idea de "infortunios sexuales de la estrella", la cual reducía lo femenino como objeto de consumo, con deseos de exhibición y excitación en los hombres, y como portadora de una "desmesura libidinosa”. Mientras que el cuerpo femenino era vedado para el goce propio, la crónica aplicaba un sentido de gusto que reforzaba el estatuto de masculinidad deseante y vigorosa sin abandonar una lectura moral sobre sus posibles efectos.

El problema de la atracción que suscitaba se convitió en un tópico recurrente en las narraciones de los críticos. Frases como "adictos de este pasatiempo; cinéfilos deformados", relevan las tensiones que existían entre quienes podían distinguir la "seriedad" cultural del cine y quienes no. Esta división era abordada en una clave moral ya que presuponía que los primeros encarnaban una ciudadanía respetable, mientras que los segundos eran configurados en oposición a ellos, en tanto legos.

En este sentido, La Nación buscó interpelar al espectador serio, a su lector asiduo, que asiste a la sala de cine para confirmar una conjetura cultural extendida: "una por lo pronto: aún es posible, en nuestro país, que una película supere la ingenuidad y la coherencia del más tosco de los teleteatros" (La Nación, 25 de septiembre de 1971). A su vez, advierte que la moralidad, entendida desde la fidelidad y la sumisión de las mujeres se pone duda en tanto "malas e indecentes" y, a su vez, enfermas. Si en Fuego se fiscalizó al cuerpo como patológico, en el conjunto de crónicas oteadas se advierte que operaba un repertorio de sentidos y representaciones en torno a lo femenino como un potencial peligroso y, en consecuencia, propenso a la insania.

A estas investiduras heternormativas le fue agregada una arenga patriarcal que invitaba a los espectadores a tomar Fuego como una lección de género: "las mujeres que cometen adulterio son enfermas y quizás se trate de un filme con moraleja: siempre conviene consultar al médico" (La Nación, 25 de septiembre de 1971). A pesar de la heterogeneidad de los registros, la parábola que las crónicas pusieron de relieve consistió en advertir de los peligros de las libertades femeninas, de la flexibilidad moral que parecía tener lugar y que los varones podían construir y compartir saberes sobre la base de la experiencia de Fuego.

De esta manera, Panorama celebró que Fuego pusiera en el centro del relato las fantasías, principalmente masculinizadas, que parecían colmar los cuerpos y las ansiedades de los espectadores. El personaje de Isabel Sarli “[...] es la efigie de un impulso que aparece como absoluto, agitada por espasmos de goce cósmico [...] es la alegoría a un deseo totalitario y voraz que no se detiene ni ante una relación lesbiana con Andrea ni ante el impulso de acariciarse y lamerse a sí misma" (Panorama, 28 de septiembre de 1971, p. 49). En ese sentido, el protagonismo sexual se asimiló en favor de los varones, cuyo deseo fue decodificado como legítimo, al tiempo que el crítico consideró como moralmente correcto el suicidio femenino representado en el filme, en tanto metáfora de redención y recomposición de la honra.

De igual manera, Análisis consideró a Fuego como un filme "sin remilgos intelectuales", y una magra línea argumental en la "que todos saben que van a ver y lo ven" (Análisis, $1^{\circ} / 7$ de octubre de 1971). En el análisis cultural, advierte que su "vulgaridad" tiene correlato en una cotidianeidad local a la que considera superflua y prosaica, producto de la emergencia de la televisión. En este sentido, esta última se percibió como el punto de culminación de un proceso de degradación cultural, contemplando el éxito y la masividad del cine erótico como un indicador que permitía diagnosticar el entramado social del momento. 
En contraposición, Crónica resaltó el carácter mítico que rodeaba a Sarli y que era éste, su halo de mito, de símbolo, el que interpelaba a las multitudes. Lejos de adscribir a la lectura moral displicente que prevalece en varias de las críticas, Crónica advertía que las acciones de censura resultaban incongruentes al contexto de los años setenta ya que "estas ya no asustan a nadie, ya que en cine se ha visto de todo" (Crónica, 3 de octubre de 1971). En este sentido, refrendó el impacto cultural y el alcance del discurso de los censores de Fuego en las salas de cine porteñas y nacionales, al difundir que al menos 111.057 espectadores habían concurrido a las salas de cine a ver al mito, al simbolo, al fuego en pantalla (Crónica, 6 de octubre de 1971).

Aunque la mayoría de las fuentes matizan el impacto cultural del cine erótico, la crítica elaborada por el Frente de Liberación Homosexual (FLH) y publicada en Panorama ofreció un ángulo de análisis disruptivo centrado en discutir el cerco conservador que signaba al sexo y la sexualidad. Como un colectivo político heterogéneo preocupado por articular la revolución social y la revolución sexual, ${ }^{10}$ la difusión del cine erótico arrojaba luz sobre el pujante lugar de la pornografía y su incompatibilidad con un proyecto de liberación sexual:

(...) la pornografía ha sido levantada por la sociedad represiva para lograr una satisfacción maldita del impulso sexual. La pornografía lleva a satisfacciones sustantivas en las cuales el sexo es vivido siempre como repugnante. $Y$ así ocurre en las películas del binomio Bo-Sarli (...). (Panorama, 19 de octubre de 1971).

Al mismo tiempo, señalaba que el cuerpo femenino oficiaba de receptáculo para volcar los sentidos peyorativos del sexo porque en el cuerpo se funge el control y el resquemor de la carne: "más allá de su carne privilegiada y pecadora, un ama de casa frustrada por su genitalidad. Cada acto sexual -generalmente llevados a cabo por hombres horribles y asquerosos- era un llamado de amor al inconsciente culpable" (Panorama, 19 de octubre de 1971).

En estas líneas, el FLH desarrolló una relación tensa con los discursos del psicoanálisis y de la sexología, como también de las jerarquizaciones culturales dispensadas por los críticos de cine. La fuente repone la complejidad de la sexualidad en la coyuntura de los años setenta en Argentina, advirtiendo la continuidad de la doble pauta de género a la hora de abordar los bienes culturales. Al referirse a la pornografía, el FLH ponía de relieve la cristalización de la matriz social represiva en el tabú antihomosexual representado en Fuego: "el homosexual masculino es ridiculizado en La mujer del intendente, y la lesbiana es pintada como maldita en Fuego" (Panorama, 19 de octubre de 1971).

La lectura del FLH desentona, en tanto recuperó el cine de Bo como pretexto para problematizar la estructura patriarcal, el androcentrismo y los resortes morales en la organización de los cuerpos subalternos. De esta manera, el cine erótico funcionaba como contradicción, en tanto se circunscribía a una matriz ideológica binaria y heterosexual, al mismo tiempo que se operaba como pliegue para el ejercicio de la sexualidad.

\section{Conclusiones}

Durante al menos tres décadas, el cine erótico y las figuras de Armando Bo e Isabel Sarli conocieron una nutrida circulación y consumo a través de diarios y revistas de la época. Dentro de su vasta filmografía, Carne y Fuego pendularon sobre el final de una década álgida en lo que refiere a los planos político, social y cultural. Al estudiar dicha década, las crónicas de cine se advierten como espacios para abordar la complejidad social de un escenario caracterizado por un fuerte autoritarismo concomitante con la flexibilización de pautas de género y en la que el cine erótico ofició como caja de resonancia de dichos nudos.

En este sentido, rastrear su alcance cultural a través de la prensa procuró entrever su lugar, y las preocupaciones suscitadas en la sociedad local en el tránsito de una década a otra. De este modo, fueron entonadas vocaciones para regular y contener el ejercicio del cuerpo y la sexualidad femenina; en paralelo, 
la noción de gusto nos permitió dar cuenta de las inquietudes y advertencias morales y androcéntricas que operaban en los críticos.

En el heterogéneo espectro de diarios, semanarios y revistas, los consumos de los sectores populares fueron identificados como un foco de preocupación ya que, en muchos casos, consideraban que su escaso capital cultural estimulaba la inclinación hacia el cine erótico y promovía una degradación cultural. Asimismo, aventuramos que dichas presunciones, ancladas en jerarquizaciones sociales, buscaban reforzar una posición subalterna de las clases populares en contextos de fuerte participación de dichos sectores (Adamovsky, 2012).

En Carne, la recepción mediática no sostuvo un despliegue lineal u homogéneo. Los diarios de mayor tirada y de tendencia conservadora, entrevieron al filme como una posibilidad de delinear un discurso androcéntrico con respecto a Isabel Sarli, su cuerpo y su moral sexual, y argumentaciones que enclasaban a los consumidores como actores legos. Estas intervenciones oficiaron de marcos de interpretación a partir de los cuales sedimentar sentidos y representaciones negativas sobre las clases populares. En esta dirección, el análisis puso de relieve cómo la rémora higienista articulada por la prensa operó como artilugio discursivo para prescribir y regular la agencia de sectores populares, tanto fuera como dentro de la pantalla.

En el caso de Fuego, la heterogeneidad de registros se centró en las implicancias materiales y simbólicas de su consumo. En sintonía con Carne, las críticas escrutaron el modelo de feminidad propugnado por Sarli y los efectos perniciosos que producirían para las audiencias y la imagen de la nación. En efecto, se propiciaba que los varones tuviesen cuidado con mujeres "activas" porque ello significaba peligrosidad para las instituciones: entre otras, la del matrimonio y la heterosexualidad. De acuerdo al diario y su anclaje en el espacio cultural, el gusto podía articular, por un lado, representaciones displicentes sobre la incapacidad de los consumidores de discernir entre arte y vulgaridad, al tiempo que alabanzas hacia la agencia femenina. Sin embargo, la crítica elaborada por el FLH propuso un contrapunto acerca del lugar de la sexualidad en los años setenta mediante un cuestionamiento a la flexibilización de la moral sexual que algunos medios consagraban en sus editoriales.

En el nivel de las representaciones, las crónicas de cine suscribieron a un bagaje conceptual cinematográfico, de índole técnico y estético, con el objeto de establecer jerarquizaciones culturales, es decir, qué era culturalmente apropiado y qué no. Asimismo, dichas operaciones aunaron posiciones en materia de género al considerar, mayoritariamente, que las mujeres debían ocupar lugares subordinados y pasivos respecto de los varones.

En consecuencia, estos documentos aportan coordenadas para analizar los actores, las ideas y los discursos que abonaron a modelar las relaciones entre género y cultura en la segunda mitad del siglo XX. En suma, queda continuar indagando los canales y los procesos de circulación, producción y resignificación que el erotismo cultural de Isabel Sarli y Armando Bó atravesó en décadas posteriores y cómo ello operó en la germinación de subjetividades y sentidos sobre la sexualidad.

\section{REFERENCIAS}

Adamovsky, E. (2012). Historia de las clases populares en la Argentina. Desde 1880 hasta 2003. Buenos Aires: Sudamericana.

Bartolucci, M. (2006). Juventud Rebelde y Peronistas con Camisa. El Clima Cultural de una Nueva Generación durante el Gobierno de Onganía. Estudios Sociales, 30(1), 127-144. https://doi.org/10.14409/es.v30i1.2573

Basilio Fabris, A. (2019). Argentina Voyeur: género, visualidad, recepción y consumo en el cine erótico de Armando Bo e Isabel Sarli (1960-1970) (Tesis de licenciatura inédita). Universidad Nacional de Quilmes, Bernal, Argentina.

Becerra, M. (2010). Las noticias van al mercado: etapas de intermediación de lo público en la historia de los medios de la Argentina. En G. Lugones y J. Flores (Comps.), Intérpretes e interpretaciones de la Argentina en el bicentenario (pp. 139-165). Bernal: Universidad Nacional de Quilmes.

Bourdieu, P. (1988). La distinción. Criterios y bases sociales del gusto. Madrid: Taurus. 
Broitman, A. (2014). Aprender mirando. Los cineclubes y sus revistas como espacios de enseñanza-aprendizaje del cine en las décadas del cincuenta y sesenta, Toma Uno, (3), 233-245. Recuperado de https://revistas.unc.edu.ar/ind ex.php/tomal/article/view/9306

Broitman, A. (2016). La trinchera de la cinefilia. Intervenciones políticas desde los editoriales de Tiempo de cine (1960-1968). Imagofagia, 14, 1-25. Recuperado de http://www.asaeca.org/imagofagia/index.php/imagofagia/ article/view/1125

Callegaro, A. M. (2014). La configuración de la reseña cinematográfica en la prensa diaria argentina (1956-1966), Figuraciones, (11), 1-6. Recuperado de http://repositorio.una.edu.ar/handle/56777/914

Calzón Flores, F. (2012). Hacia una reconstrucción de las revistas del espectáculo: el caso de Radiolandia en los cuarenta y cincuenta. Temas de Historia Argentina y Americana, 20, 41-63. Recuperado de https://repositorio.uca.edu.a r/bitstream/123456789/7213/1/hacia-reconstruccion-revistas-espectaculo-radiolandia.pdf

Cammarota, A. (2014). Somos bachiyeres. Juventud, cultura escolar y peronismo en el Colegio Nacional Mixto de Morón (1949-1969). Buenos Aires: Editorial Biblos.

Campos, J. (2016). Mirada a distancia: la crítica cinematográfica argentina revisa los filmes mexicanos (1930-1960), Revista F@ro, 1(23), 356- 381. Recuperado de https://www.revistafaro.cl/index.php/Faro/article/view/474/ 435

Cane, J. (2012). The fouth enemy. Journalism and power in the making of peronist Argentina, 1930-1955. Pennsylvania: Pennsylvania State University Press.

Capalbo, A. y Valdéz, M. (2004). Amor constante más allá de la pantalla. Armando Bo e Isabel Sarli en Columbia Pictures. En C. España (Dir.), Cine Argentino. Modernidad y Vanguardia, 1957-1983, Tomo II. Buenos Aires: Fondo Nacional de Las Artes.

Chartier, R. (1991). El mundo como representación. Historia Social, 10, 163-175.

Cousins, C.S. (2008). El General Onganía y la Revolución [Militar] Argentina de la derecha: anti-comunismo y moralidad, 1966-1970. Historia Actual Online. 17 (1), 65-79. Recuperado de https://www.historia-actual.org/ Publicaciones/index.php/hao/article/view/268

Cosse, I. (2010). Pareja, sexualidad y familia en los años sesenta. Buenos Aires: Siglo XXI Editores.

Cosse, I. (2012). El nuevo periodismo y el estatus de la apertura cultural. Nuevas formas de sociabilidad en Argentina (1962-1969). En M. Maronna (Comp.), Historia, cultura y medios de comunicación. Enfoques y perspectivas (pp. 93-108). Uruguay: Biblioteca Nacional.

Cutuli, R. (2011). "Feas, sucias y malas". Miradas "de" y "sobre" las trabajadoras del sector pesquero (Mar del Plata, 1990-2010). Ankulegi, 15, 141-157. Recuperado de https://aldizkaria.ankulegi.org/index.php/ankulegi/article /view/45

D’Antonio, D. y Eidelman, A. (2019). Cultura, sexualidad y censura estatal en el cine de Argentina y Brasil entre los años 1960 y 1980. Mora, (25), 111-134.

Drajner Barredo, T. (2016). ¿Cosificación o uso político? Carne de Armando Bo-Isabel Sarli. Imagofagia, 14, 1-27. Recuperado de http://asaeca.org/imagofagia/index.php/imagofagia/article/view/1105/977

Eidelman, A. (2015). Moral católica y censura municipal de las revistas eróticas en la ciudad de Buenos Aires durante la década del sesenta. En D. D’Antonio (Comp.), Deseo y Represión. Sexualidad, género y Estado en la historia argentina reciente. Buenos Aires: Imago Mundi.

Eujanian, A. (1999). Historia de las revistas argentinas. 1900/1950. La conquista del pueblo. Asociación Argentina de Editores de Revistas: Buenos Aires.

Ford, A. y Rivera, J. (1985). Los medios masivos de comunicación en la Argentina. En A. Ford, J. Rivera y Romano, E. (Ed.). Medios de comunicación y Cultura Popular (pp. 24-45). Buenos Aires: Legasa.

Foster, D. W. (2008). Las lolas de la Coca: el cuerpo femenino en el cine de Isabel Sarli, Karpa: Dissident Theatricalities, Visual Arts and Culture, 1(2), 1-6.

Getino, O. (2008). El capital de la cultura. Las industrias culturales en la Argentina. Buenos Aires: CICCUS. 
Gil Mariño, C. (2013). La argentinidad del buen gusto. Imágenes de lo popular y lo nacional en la prensa de cine de los años treinta. Montajes, 2, 75-93. Recuperado de http://www.revistamontajes.org/?p=941

Giordano, V. (2014). El erotismo en las páginas de Adán, 1966-1968. Caiana, Revista de Historia del Arte y Cultura Visual del Centro Argentino de Investigadores (CAIA), 4, 1-9. Recuperado de http://caiana.caia.org.ar/templa te/caiana.php?pag=articles/article_2.php\&obj $=134 \&$ vol $=4$

Goity, E. (2004a). Medios y críticos, entre 1957 y 1960. En C. España (Dir.), Cine Argentino. Modernidad y Vanguardia, 1957-1983, Tomo I. Buenos Aires: Fondo Nacional de Las Artes.

Goity, E. (2004b). Las batallas calientes. Armando Bo edifica a Isabel Sarli. En C. España (Dir.), Cine Argentino. Modernidady Vanguardia, 1957-1983, Tomo I. Buenos Aires: Fondo Nacional de Las Artes.

Goity, E. (2004c). Publicaciones y críticos. El comentario analítico intentó el magisterio autorial. En C. España (Dir.), Cine Argentino. Modernidad y Vanguardia, 1957-1983, Tomo II. Buenos Aires: Fondo Nacional de Las Artes.

Hall, S. (1997). The work of representation. En S. Hall (Ed.). Representation: cultural representations and signifying practices (pp. 13-75). Londres: SAGE.

Iturralde, M. y Borrelli, M. (2019). Trasvasamiento generacional no es trasvasamiento ideológico. La revista Extra y el conflicto interno en el peronismo (1973-1974). Trabajo y Comunicaciones, 50, 1-19. https://doi.org/10.242 $15 / 23468971 \mathrm{e} 093$

King, J. (2012). "Ya nunca más seríamos lo que éramos": Tomas Eloy Martínez and Primera Plana in the 1960s. Bulletin of Latin American Research, 31(4), 426-444. https://doi.org/10.1111/j.1470-9856.2012.00767.x

Lobato, M. (2004). La vida en las fábricas. Trabajo, protesta y politica en una comunidad obrera, Berisso (1904-1970). Buenos Aires: Prometeo.

Lobato, M. (2019). Dentro y fuera del lugar. Carne, trabajo e identidades de género en Argentina. En J. Suriano y C. Schettini (Comps.), Historias Cruzadas. Diálogos historiográficos sobre el mundo del trabajo en Argentina y Brasil (pp. 29-66). Buenos Aires: Teseo.

Manzano, V. (2017). La era de la juventud en Argentina. Cultura, política y sexualidad desde Perón hasta Videla. Buenos Aires: Fondo de Cultura Económica.

Milanesio, N. (2010). Food politics and consumption in Peronist Argentina. Hispanic American Historical Review, 90(1), 75-108. https://doi.org/10.1215/00182168-2009-091

Montrucchio, M. (2000). Hojeando al peronismo en Primera Plana: una historia sui generis en los años sesenta. Sociohistórica, 8, 45-82. Recuperado de https://www.sociohistorica.fahce.unlp.edu.ar/article/view/SHn08a02

Panella, C. (2000). El peronismo según el Diario La Prensa en tiempos de la Revolución Libertadora (1956-1958). Anuario del Instituto de Historia Argentina, 1, 109-122.

Pujol, S. (2007). Rebeldes y modernos: una cultura de los jóvenes. En D. James (Dir.), Violencia, Proscripción y autoritarismo (1955-1976), Tomo IX (pp. 281-327). Buenos Aires: Sudamericana.

Osuna, M. F. (2017). La intervención social del Estado. El Ministerio de Bienestar Social entre dos dictaduras (Argentina, 1966-1983). Rosario: Prohistoria Editores.

Oubiña, D. (2016). Una política de autores para Latinoamérica. (Nuevos cines y nueva crítica: Argentina, Brasil y México en los sesenta), Kamchatka. Revista de análisis cultural, 8, 347-361. https://doi.org/10.7203/KAM.8. 9022

Ramírez Llorens, F. (2013). Católicos entre el mercado y el estado: la calificación moral de películas por parte de la dirección de cine y teatro de la Acción Católica Argentina. Secuencias, 37, 83-103. Recuperado de https://revi stas.uam.es/secuencias/article/view/5884

Rein, R. y Panella, C. (2008). Peronismo y prensa escrita. Abordajes, miradas e interpretaciones nacionales e internacionales. La Plata: Edulp.

Ruétalo, V. (2004). Temptations: Isabel Sarli exposed. Journal of Latin American Cultural Studies, 13 (1), 79-95. ht tps://doi.org/10.1080/1356932042000186505

Schaufler, M. L. (2017). Erotismo y mediatizaciones. Revistas femeninas en la Argentina de la década del 60. Inmediaciones de la comunicación, 12(2), 173-197. 
Scott, J. (2008). Género e Historia. Ciudad de México: Fondo de Cultura Económica. https://doi.org/10.18861/ic. 2017.12.2.2700

Segato, R. (2003). Las estructuras elementales de la violencia. Ensayos sobre género entre la antropología, el psicoanálisis $y$ los derechos Humanos. Bernal: Universidad Nacional de Quilmes.

Simonetto, P. (2017). Entre la injuria y la revolución. El Frente de Revolución Homosexual Argentina 1937-1976. Bernal: Universidad Nacional de Quilmes.

Tenti, M. M. (2012). Los estudios culturales, la Historiografía y los sectores subalternos. Trabajo y Sociedad, 16 (18), 317-329. Recuperado de https://www.unse.edu.ar/trabajoysociedad/18\%20TENTI\%20Estudios\%20culturale s\%20e\%20historiografia.pdf

Terán, O. (1991). Nuestros años sesenta. La formación de la nueva izquierda intelectual en la Argentina 1956-1966. Buenos Aires: Puntosur Editores.

Terán, O. (2008). Historia de las ideas en la Argentina: diez lecciones iniciales 1810-1980. Buenos Aires: Siglo XXI Editores.

Ulanovsky, C. (1997). Paren las rotativas. Una historia de los grandes diarios, revistas y periodistas argentinos. Buenos Aires: Emecé.

Varela, M. (2005). La televisión criolla. Desde sus inicios hasta la llegada del hombre a la luna, 1951-1969. Buenos Aires: Edhasa.

Wacquant, L. (2002). El suicidio de Bourdieu, Cuestiones de Sociología, 1. Recuperado de https://www.cuestionessoc iologia.fahce.unlp.edu.ar/article/view/CSn01a12/5228

Zanca, J. (2010). La Fe de Prometeo. Crítica y Secularización en el catolicismo argentino de los años cincuenta. Prismas, 14(1), 95-114. Recuperado de https://historiaintelectual.com.ar/OJS/index.php/Prismas/article/view/Zanca_ prismas 14

\section{FuENTES PERIODÍSTICAS}

Agenda cine. (29 de octubre de 1968). Panorama.

Calentamo el ambiente. (28 de septiembre de 1971). Primera Plana.

Carne. (26 de octubre de 1968). La Prensa.

Carne. Presentada en el Hindú. (26 de octubre de 1968). Crónica.

Carta abierta de Armando Bo a los críticos cinematográficos. (3 de abril de 1980). Convicción.

Cartelera. (1\%/7 de octubre de 1971). Análisis.

Con el correr de los años. (28 de septiembre de 1971). Panorama, p. 49.

El adivino. (21 de agosto de 1969). Confirmado.

Emotivo drama del suburbio porteño. (25 de octubre de 1968). La Razón.

Fuego. (24 de septiembre de 1971). La Prensa.

Fuego. (24 de septiembre de 1971). Radiolandia.

Fuego. (5 de octubre de 1971). Primera Plana.

Fuego. Peculiar reflejo de un caso clínico. (25 de septiembre de 1971). Clarín.

Isabel Sarli en un dramático relato. (24 de septiembre de 1971). La Razón.

Isabel Sarli prende "Fuego" en los cines. (6 de octubre de 1971). Crónica.

La muchacha que no era mala sino enferma. (25 de septiembre de 1971). La Nación.

Las paradojas de la censura (19 de octubre de 1971). Panorama.

Panorama de Cine y la TV. (28 de octubre de 1969). La Prensa.

Pulido. (3 de octubre de 1971). Crónica.

¡Prohibida en Argentina! ¡Aclamada en Uruguay! (17 de octubre de 1970). La Nación. 
Prueba de Fuego para Isabel Sarli. (11 de septiembre de 1971). Crónica.

Refriegas en un frigorífico por una mujer. (26 de octubre de 1968). La Nación.

Relato pleno de pasiones y violencia. (10 de noviembre de 1968). Radiolandia: el estreno de la semana

Retozos eróticos de Isabel Sarli en un perseguido film de Armando Bo. (25 de septiembre de 1971). La Opinión, p. 21.

También se estrenaron. (31 de octubre de 1968). Confirmado.

Triunfa en Montevideo un filme de Isabel Sarli. (15 de octubre de 1970). La Razón.

\section{Notas}

1 En este artículo, excluimos del análisis la circulación transnacional de la pareja y su cine debido a que excede los alcances de nuestra investigación (Basilio Fabris, 2019). Sin embargo, en las próximas páginas se aludirá a esta dimensión a los fines de comprender los escenarios históricos de ese entonces.

2 Para ahondar en la relación entre Martínez y Primera Plana, véase King (2012).

3 Cinegraf fue una publicación de la Editorial Atlántida que se editó entre 1932 y 1937.

4 Según Gil Mariño (2013) ambas plataformas coexistieron en la década del treinta, pero urdieron distintos intereses y objetivos: mientras que la primera buscaba instalar una lectura más sofisticada sobre el cine, para advertir la falta de "buen gusto" en la cinematografía nacional; la segunda anudaba un lenguaje coloquial utilizando tanto elementos técnicos como los entramados populares propios del momento.

5 De acuerdo a Natalia Milanesio (2010), la comida, y sus políticas de consumo y acceso también coadyuvaron en la construcción de símbolos y significados acerca de la familia, el Estado y la nación durante el peronismo.

6 La trayectoria periodística de Jaime Potenze fue extensa tanto en relación con la crítica de cine como con la revista Criterio, órgano de difusión de la Acción Católica Argentina (ACA). Para analizar la articulación de la militancia católica laica y el espectáculo, véase Zanca (2010); Ramírez Llorens (2013).

7 De acuerdo a las fuentes recabadas, la Gaceta de los espectáculos contaba con un cuadro clasificatorio cuyos ítems condensaban una escala de valores diseñados en círculos: un círculo era sólo complemento; dos círculos regular; tres círculos, buena; cuatro círculos, muy buena; y cinco círculos, de óptima a excepcional. Estos valores, a su vez, se colocaban para hablar de la recaudación en taquilla y de la calidad del largometraje.

$8 \mathrm{El}$ análisis sobre las alocuciones entre sexualidad, discurso biomédico y la reapropiación hecha del cine erótico local ameritan una consideración más extensa que, en consecuencia, exceden los objetivos del presente trabajo. No obstante, dicho estudio emerge en mi tesina de grado.

9 Para analizar el impacto del discurso biomédico en la regulación de la sexualidad, véase Ramacciotti y Valobra (2008).

10 Para analizar la trayectoria del FLH, véase Simonetto (2017). 